\title{
Plan and project as resistance strategies. Didactics, planning and designing in a continuous changing era
}

\author{
Paola Pittaluga*
}

\begin{abstract}
The transformation of physical spaces by means of plans and projects requires knowledge and understanding of what needs to be transformed. In this sense, project work is influenced by the way we get to know things and learn. This way is in turn strongly influenced by the wider socio-cultural context in which we are educated. Cultural debate about learning modalities in the era of "liquid modernity" evidences an epistemological change and a worrying aspect that involves the project-oriented ability of individuals: no person can have experience of stability and it is impossible to design the change. What, then, is the future for all those activities that plan change and transformation? Maybe the answer can be found in imagining the traditional instruments of space transformation, namely plans and projects, as "resistance strategies". A idea like this implies "resistance" at various levels by an approach to the plan and project that retrieves some of the connotations lost over time and takes on new ones more suitable to these times of crisis: the plan and the project as an instrument of knowledge, as a means of structuring elements of permanency, as an instrument of opposition to standardisation and to steered market forms, and as an activator of forms of collective management.
\end{abstract}

Keywords: Planning and architecture, Learning modality and design capacity, Resistance strategies

\section{Introduction: Project work and learning method}

The transformation of physical spaces by means of plans and projects requires knowledge and understanding of what needs to be transformed. In this sense, project work is influenced by the way we get to know things and learn. This way is in turn strongly influenced by the wider socio-cultural context in which we are educated.

The last years of the Twentieth century and these early years of the Twenty-first have been characterised by an epistemological change in the ways of learning described by Bauman, based on Bateson's ideas (Bateson 2000), and those of other authors (Manghi 2003, 2004; Melucci 2000; Possenti 2008) in the era of liquid modernity (Bauman 2002a).
According to Bateson there are four levels of learning, identified from A0 to A3. Level A0 is the level of habit automatism, level A1 corresponds to learning, correct use of the habitual thought categories such as, for example, the correct classification of information. The third level, A2, is learning to learn: recognition and acquisition of new, diverse epistemological habits and categories not included among those that guide us more spontaneously. The last level is A3, learning to unlearn: capacity to relativise at any moment the more spontaneous thought categories that are also being dynamically employed, and to keep categories linked with each other, although these categories are highly heterogeneous, alternative and divergent (Manghi 2003).

Level A3 for Bauman includes the skills that enable an individual to modify the set of alternatives he has learnt to expect and master (Bauman 2002b). It is learning to violate compliance with the rules. And Bauman states that success in life (and therefore rationality) of postmodern men and women depends on the speed with which 
they manage to get rid of old habits rather than that by which they acquire new ones.

Level A3 is difficult to formalise (Bateson 2000), however, as it enjoys the "logical" requisite according to which the subject involved in this level of learning is unaware of the change underway.

Actually, for Bauman, learners in liquid modernity are prepared to miss out level A2, thus running some risks linked with the difficulty of associating many different themes and aspects, poor autonomy and critical capacity, the inability to build up accumulated knowledge to be reused in other contexts and the incapacity to reconstruct the learning process due to the difficulty of making deep knowledge explicit, but also the superficial used during action, and the constant rejection of the rules.

Possenti (2008) wonders if tertiary learning might not lead to training personalities that are apathetic, unstable or schizophrenic. For Bauman, this risk is not run since abnormality represents a norm in our current society, so educating towards flexibility, basically meant as casting off cognitive habits, would in no way constitute a distortion of the education process, but a fundamental objective of postmodern education.

But how can this theory, in which Bauman encourages educating towards cognitive flexibility founded solely on the creative potential of tertiary learning (Bauman 2002b), stand up without level A2 learning? How, in fact, is it possible to learn to unlearn if one has not learnt to learn first? In this case one would have a set of notions, data, disorganised concepts and the continuous replacement of pure and simple cognitive content (Possenti 2008). No integration of the information on a cognitive map would be possible in this way, nor autonomous, reflective management of the knowledge acquired. The only formative objective effectively pursued in such a situation would be to educate people to carry out executive tasks (Possenti 2008).

A further worrying aspect of liquid modernity and of tertiary learning arises, however, that involves the project-oriented ability of individuals: when one can never have the experience of stability, it is impossible to design the change.

\section{Didactics, planning and designing in a continuous changing era}

What, then, is the future for all those disciplines, like architecture and planning, that design change and transformation?

How can design students exercise in the transformation of city, environment and landscape, if they do not experience stability? Is it possible, to transform something that is perceived and experienced as endlessly changing? Are design and its teaching still possible?
I believe that an approach to design and planning teaching based on "learning by doing" (Dewey 1916) and on "reflecting during the course of action" (Schön 1983) can give an answer, along with reconsidering planning and design, the traditional tools of space configuration, as "resistance strategies" against the liquidness of contemporary world.

Teaching based on "learning by doing" and on "reflecting during the course of action" is not anything new, but it becomes ground-breaking when connected with the need of interdisciplinarity in planning and design. Until few years ago planners and designers had still the option to disregard the need of communicating with other disciplines. Climate change and economic crisis make impossible to ignore this need anymore, and the lessons about complexity and interaction proper of environmental, economic and social sciences.

Plans and projects as "resistance strategies" are tools able to withstand against the current learning modalities and dampen their consequences. They are at the same time an essential part of the design process.

Plans and projects as "resistance strategies" retrieve some of the connotations lost over time and take on new ones more suitable to these times of crisis, operating at different levels: at the level of knowledge-plan and project as instruments of knowledge; investigation in permanence and durability-plan and project as resistance against oblivion and structuring elements of permanence; at the level of increasing diversity-plan and project as opposition to standardisation and to steered market forms; at the level of managing transformation-plan and projects as activators of forms of collective management.

Why are these strategies needed?

Because every transformation starts from a steady state: otherwise it would be like trying to change the form of water without using any container. In order to bring back the A2 level some steady points are needed (resistance to oblivion and the organization of elements of permanence and stability) as well as some strategies to improve critical judgement (i.e., resistance to be hetero-directed by market, forces from outside a given context,...), increase independence, incremental knowledge, assist in building links between different fields of knowledge, topics and issues, the acceptance of rules.

In the last 10 years of teaching, I very often observed this lack of skills and difficult condition in my students.

The majority of them do not usually recall concepts acquired in other classes, if not explicitly requested to. They put aside, and sometimes lose, all their previous knowledge because they view it as immediately obsolete, and thus develop the design assignments in an objectual, often non-contextual way. Moreover, they often approach the design studio as a sequence of routines, as an almost 
automatic workflow, trying to slavishly transpose the notions acquired through lectures.

We must then consider plans and projects not only as tools to anticipate the physical transformations of our life spaces, but as tools to experience steadiness, resisting to all the forces that undermine it.

The next paragraphs will explain the various levels of the idea of the plan and the project as resistance strategies, allowing the capacities inherent in level A2 to develop, in a didactics following the principles of learning by doing, of reflecting during the course of action, and experimenting stability.

There will be a highlight of the contribution of each level when dealing with the consequences of ignoring or not fully acquiring the A2 level, showing how, in some cases, planning and design are approaches that converge to the same direction, even when they start from different considerations.

\section{Plan and project as an instrument of knowledge}

The first level of resistance-plan and project as an instrument of knowledge-acts on educating subjects to be able to carry out tasks that are not simply executive (according to Possenti, ignoring the level A2 could cause the loss of this skill), and considers the project a cognitive activity able to oppose forces that destroy and impoverish part of the potential inherent in knowing and in knowledge, when these are nothing more than a mere accumulation and stratification of non-related/relationable notions.

Actual design activity, the one that effectively transforms the real world, is interdisciplinary by necessity, as it needs a framework to integrate different information coming from different disciplines, more or less contiguous. Planning and design need to understand the consequences of physical transformations and of the presence of new elements in the urban or territorial space. They do not rest on absolute theories and paradigms and cannot be acquired through scientific experiments. Thus design cannot become, if not marginally, a confused list of simple actions purely derived by notions, nor can it build on knowledge as the simple sum of data and information that never, or rarely, enter into contact, stored in watertight compartments, or to specific knowledge like those typical of academic disciplinary fields.

An adequate teaching of design and planning should mimic the interdisciplinary dimension and implement it through an interdisciplinary didactic framework where specific classes concur in developing the main theme through a design studio. Learning by doing and reflecting during the course of action become thus applicable and transmissible.

In this sense, plan and project become resistance instruments to forms of notional and strictly monodisciplinary knowledge and take on a relational meaning and an exploratory/operative one.

The relational meaning precisely refers on the one hand to an interdisciplinary approach to the project-oriented culture space transformation, organisation and management, in which different fields of knowledge intertwine, giving life to hybrid, liminal situations.

These situations are spaces of co-presence among of various dimensions (cultural, political, temporal, social, historic, etc.) and in-between spaces (or "third spaces") (Bhabha 1990; Routledge 1996; Soja 1989, 1996, 2000) that represent laboratories for change (Alvarex 1995; Blatter 2003; Smouts 1998; Tangkjær and Jonsson 2005), for encountering otherness (Gupta and Ferguson 1997; Gutierrez 1999, Turner et al. 2003), spaces of communication, negotiation and shifting from one perspective to another (Bhabha 1990, 1994, 1996), which favour relational ways of constructing knowledge (Morin 2011).

On the other hand, relational meaning introduces different aspects, facts and knowledge, in order to create synergies, complementarity and "reliance" (Morin 1997), namely the ability to link up types of knowledge with each other and the global with the local.

Relational meaning sees the project as an opportunity for cooperative construction of knowledge: architect and planner are no longer monads, individuals capable of managing and implementing the project process in a solitary, totally autonomous manner, but need to resort more and more to experts in various sectors with whom, however, they need to be able to converse and compare notes. Through this dialogue and comparison a form of cooperative knowledge originates that is more than the simple sum of the single parts.

This is how the knowledge that is said in the literature to derive from collective intelligence, or also connective intelligence, is built up. De Kerckhove (1997, 2001), in particular, defines connective intelligence as a form of collaboration and cooperation between different subjects (individuals or groups), obtained by sharing and dialogue, which generates learning or innovation, improving skills and performance at an individual and systemic level, and differs from "collective" intelligence because each subject keeps his own identity during the sharing and dialogue, albeit within the sphere of a very articulate, extended framework of connections. ${ }^{1}$ This kind of knowledge is the typical outcome of an interdisciplinary planning or design process.

The second meaning of plan and project as resistance strategies and instruments of knowledge is exploratory/ operative in the sense that project is means by which the context in which one operates becomes known; they

\footnotetext{
${ }^{1}$ For further study see also Tagliagambe (2008).
} 
become useful "probes" to understand the physical, cultural and social space one is acting upon and to reflect during the course of action. This meaning enriches the preliminary traditional analysis, for the collection of information a priori obviously gather all the information and aspects that exist, are latent and possible. Above all, this meaning stimulates the social reactions and responses of the context in which one is operating that are not obtained by simple reconnaissance, since this will not produce the transformational effects that, on the other hand, project generates. To be more precise, the acquisition of common knowledge, the investigation of problems, desires and expectations of a group of individuals, and the evaluation of their appreciation of a hypothesis for transformation produces different outcomes if one finds oneself within a true planning process, and these hypotheses can actually be carried out.

Design as a "probe" allows "learning to learn", because it traces and frames an exploratory route to a precise destination within an unknown context, evaluating which options and actions could be effectively deployed. Designers learn to learn how to select the fundamental information, not all the available ones, how to stimulate and understand the reactions of the context and of future users, how to work in uncertain conditions. In short, they learn to build up a methodology, an approach, an ethic, and a critical knowledge to effectively plan and design.

\section{Plan and project as resistance to oblivion and as strategy structuring the elements of permanency}

A second level of "resistance" is constituted by the plan and project as resistance to oblivion and as strategy structuring the elements of permanency in an ever-changing world, as resistance to uncertain, fleeting situations that indeed do not enable an experience to be had of stability. In this case, plan or project becomes an instrument to cast anchors, create reference points or cornerstones ${ }^{2}$ from which to depart to define transformations that will incorporate and perpetuate them, although keeping the flexibility needed to come to terms with a steadily evolving world.

Finding and structuring elements of permanence allow students to notice the elements that could keep their stability over time, both physical (like religious sites, historic buildings,...), and immaterial (functions, meanings, values), or that change in time according to patterns and rules.

\footnotetext{
${ }^{2}$ I would like to mention here that constraint is a possibility (Cfr Ceruti 1986), that resistance based on maintaining certain fixed points, on some elements of permanency, principles and values that have been passed down and that last over time is a constraint that opens up new possibilities. This also refers to the meaning of innovation as provided by Silvano Tagliagambe - an unusual combination of elements of a given world-and to the idea that we should understand the principle of freedom not as the absence of impediments but as a project (Cfr. Gregotti 2008).
}

A vision of the project that becomes anchored to "permanency", to roots and identity, does not mean a separate, localist conception turning in upon itself and conservative, but a capacity to go beyond and develop, maintaining indeed its own identity, as happens with living systems, in their autopoietic conception.

This means basing the project on ethics caring for the values of environmental history, sustainability, respect for what has always-been (compared with what is not-yet) (Palermo 2000), and opposing that minimum of resistance that, though permitting change and transformation of our life spaces, maintains their deepest identity, with an implicit resilient, autopoietic strategy.

This type of ethics may be strongly linked with the environmental dimension and the landscape of the physical context in which one is operating or with a more urban, material dimension.

In the first case the anchors, the still points are places or place systems whose importance is not simply, or solely, linked with the naturalistic value in a strict sense, or with aesthetics or size, but with the capacity of these places to modify, influence or define, also symbolically, the physical context and its spatial organisation.

These places or place systems are "environmental dominants" (Maciocco 1995), places rich in nature and history (Maciocco 1999), "structure territories" that link them (Maciocco 2011), and become elements of resistance to overcome that worrying aspect of liquid modernity and tertiary learning by virtue of which we cannot design and thus transform if we do not understand, know and experience stability and permanency.

In the second case, in which the project is involved in a more urban, material kind of ethics, resistance may also be offered by the "primary urban facts" recognised in places and buildings of the memory: for the memory is not a static repertory of past objects; it is the awareness of a process that has been, but continues into the present and the future (Rossi 1966).

The elements of resistance that the cultural, environmental-historic identity of our life spaces reveals are not enough, however, if they are not also accompanied by elements deriving from knowledge not solely technical. Once more the interdisciplinary approach, hybridisation and recognition of the importance of the existence of different forms of rationality require common and contextual, not expert, knowledge. Common knowledge, knowledge expressed by the people that inhabit a territory, guides us in recognising images of space organisation and spatial elements that have always constituted the elements of permanency and identity. Common knowledge also guides us in producing and encouraging a sense of rooting and belonging to the urban territorial contexts in question, so as to hinder the alienation and 
bewilderment emphasised by standardisation and globalisation processes.

For each local society that inhabit a territory shared maps exist, as explained by environmental psychology, on which the places of their vital space are represented, the relations between them, their organisation and their fruition (Pittaluga 2001, 2008). Projects reduce instability and uncertainty, and are configured as resistance strategies if they gather and incorporate elements coming down from these shared maps of the local society. Shared maps are established through a process of "territorial hysteresis" in which the environmental dominants emerge, the significant places, non-negotiable values and elements of long duration (in particular the relations) that have always presided over the space organisation of a society.

\section{Plan and project as an instrument of opposition to standardisation and steered market forms}

The project as a strategy structuring elements of permanency, described in the previous paragraph, is not only a simple act of conservation, but also means the reconstruction of a system of resistance, constructing and defending spaces for slowing down against a reality that is rapidly fluctuating, hetero-directed and market-linked (Gregotti 2006). According to Frampton (1983), critical regionalism also moving in this direction and proposed "resistant architecture" against prevailing consumerism and centralised power and control (Frampton 1986), opening up to an idea of the environment and the landscape as an instrument to resist the globalising, standardising tendencies (Shannon 2006).

Thus design becomes an exercise to avoid the risks of ignoring the A2 level, avoiding poor autonomy and scarce critical capacity. Design and planning become tools to withstand pervasive homologation, planned obsolescence, global market imperatives, and help students to reflect about questions, about consequences and how to build a critical judgement and a different view on things surrounding us.

Moreover, students learn, and learn to learn, how to build a critical and free point of view to evaluate models, and images imposed or suggested from outside.

A certain type of architecture and planning ${ }^{3}$ that in some cases had Lefebvre's theories of the importance of the everyday as its cultural reference base, contribute to pursue an educational and professional activity "critical" and "durable" as well as activism and informal

\footnotetext{
${ }^{3}$ See Spatial Agency, a project that presents a new way of looking at how buildings and space can be produced. Moving away from architecture's traditional focus on the look and making of buildings, Spatial Agency proposes a much more expansive field of opportunities in which architects and nonarchitects can operate. It suggests other ways of doing architecture. http:// www.spatialagency.net/.
}

practices-in general all those alternative approaches that put in first place not the built object but that "interpretative and critical act" (Colomina 2002), which opens up to new perceptions, possibilities or the process of architectural production that includes the user, too (Guattari 1996; Hill 1998a, b, 2003; Kronenburg 2007; Mitchell 1993).

Sometimes they are such radical approaches that they have political and empowerment aims, like insurgent planning, guerilla urbanism or the design theories and experiments inspired by an "insurgent architect" (Harvey 2000), able to create pioneer forms of existence by combining practical spirit and visionary capacity. These are approaches which imply knowing how to define or break rules.

To think today of resistant project (or design) that opposes the mainstream, linked with hetero-directed and uncertain reality as indicated previously, also means to take one's distance from the project-oriented approaches based on the thematisation and spectacularisation of space and its functions, and from the interventions and architectural objects tending towards the construction of simulacra that might substitute it.

Spectacularising forms of urban planning and architecture also trigger processes of gentrification transform space and buildings into useful objects for intense media and ideological activity, simulacra devoid of content and therefore pure images subjected to superficial perception, as arises, for example, with historic town centres but also, generally speaking, with the historic, cultural and landscape patrimony, which become the objects of more or less decontextualised consumption, or like an object whose true context is the world of planetary circulation (Augé 2003).

Urban make-up and urban or environmental marketing are the more extreme forms, aimed at tourists so that they can enjoy such a perfect image as to make the urban landscape seem the one on the postcards. The final result is so artificial that even the local identity becomes false, a simulacrum, and not reality, since it reconstructs reality based on its simulacrum, from the image that the "world" has of the object, a reality that no longer exists (time passes) though everything is apparently as it was before.

These distortions are also found in some territorial, landscape and tourist policies. They are superficial environmentalist positions, based on nostalgic visions of a "green-worshipping" (Roger 1997), world, romantic and overly refined, which brings to mind various approaches, from the one considering the landscape a museum and crystallised, to the more exaggerated forms of urbanism, landscape scenic beauty aesthetic value.

The project-oriented attitude that progresses by assigning themes to landscapes, but also to architecture, by 
building simulacra, no longer represents an exception but if anything a constant, favoured, as Sorkin $(1999,2001)$, maintains, by processes of space privatisation to the detriment of the public space-increasingly unsustainable from an institutional point of view-of commercially standardised places for selling and consuming.

All these approaches have seductive ability and economic power to distract designers from critical thinking, from working out specific solutions for a given context, and they overall prevent them from using planning and design as a knowledge tool.

These disciplinary positions do not, however, favour authentic quality of life of the inhabitants, as they often generate unfamiliar spaces or ones to be admired at a distance, beautiful but devoid of the value, meaning and feeling of attachment that only everyday use can give to make them real, lived-in spaces. These approaches prevent designers from understanding the perceptive worlds of local societies previously mentioned, and from delineate proposals effectively addressed to real users.

Designers thus, lacking critical judgement, configure space following hetero-directed models, because conventional architecture and a traditional concept of planning trap and influence them. The space proposed by the media of the star system, plays a great role, as it is spectacular or meant to be gazed upon, in which the relationship with the user is standardised, based on an abstract, passive subject.

The value and sense are self-referential, as if the designer were working for his sole satisfaction and not for another subject, be it individual or collective.

In actual fact, it is this collective subject that determines the significance and sense and thus the capacity of project practice to regenerate space, in particular public space, and to favour processes of appropriation of space and consequently urban reorganisation. The role of the designer is fundamental but remains hidden, unrecognisable: renown is sacrificed to a form of ethics that grants users the role of protagonists, thereby refusing the logics of branding, be it connected with an economic, institutional, political or personal subject.

\section{Plan and project as an activator of forms of collective management}

In the previous paragraph about planning and design as tools to withstand homologation and the imposition of hetero-directed behaviours, the reference to a collective dimension ${ }^{4}$ introduces the concept of plan and project as an activator of forms of collective management, a resistance strategy towards hetero-directed, self-celebratory

\footnotetext{
${ }^{4}$ Aldo Rossi (1966) means architecture in the positive sense, as a creation inseparable from the civil life and society in which it is manifest; it is by nature collective.
}

forms of organisation and management of space in which planning and architecture go back to being a prerogative of people, for people.

The broadening of knowledge building approaches is the contribution that collective forms of management (and the collective dimension in general) bring to the learning process and to design and planning teaching, because knowledge is not simply an accretion of notions, but the ability to establish links between them and to frame them within a collective process.

Designers and students learn to come to terms with local society, experiencing different kinds of knowledge, forms of rationality, ways of thinking.

Participatory, communicative and collaborative planning and design are the key disciplines during this kind of activity, along with more radical approaches, like equity planning or insurgent planning.

These approaches also contribute to describe an idea of project as an instrument of resistance to the forms of the discipline based on those models that exclude, are hetero-directed and imperative, and in some cases repressive, that see in the final user an acritical subject, passive and incapable of showing his own planning and designing ability and the capacity to autonomously take care of the space in which he lives, be it city, country or landscape, through forms of collective transformation and management of our life spaces (Pittaluga 2013).

The latter are relevant for this topic for two reasons. On one side, public property is unable to conserve, maintain and manage the contexts in which we live and the services we need. In other words, the transformation of the common or collective good into private property is becoming the way to solve economic problems, both related to the care of the good and in general terms. ${ }^{5}$ Thus, environment, culture, history, identity and landscapes are sold: for example the securitization of the historical and architectural heritage and the environment by the Italian government. ${ }^{6}$

Public space, the historical and architectural heritage, environmental resources and the landscape can be considered as collective goods or goods subject to "diffuse ownership", which belong to everyone and no-one, in the sense that everybody should have access to them and no-one claim them exclusively. They must be managed according to the principle of solidarity. They incorporate

\footnotetext{
5 To overcome the crisis the Italian government also relies on the sale of environmental public goods, as well as historical and archaeological heritage. Article 7 of the Law of 12 November 2011 provided for the sale of State-owned land in a very brief period, including agricultural land (by subsequent amendments of 2012), leading to a phenomenon already strongly present outside our country, namely land-grabbing, by economically and politically stronger subjects.

${ }^{6}$ http://www.limen.org/BBCC/tutela/Conservazione\%20delle\%20citt\%E0/ Censimento\%20patrimonio/Legge\%20112\%20de\%202002.
} 
the future dimension, and should therefore be governed also in the interests of future generations (Rodotà 2010).

As they are goods with widespread ownership, before handing over to private, it is possible to think of transforming and managing them using an alternative, hybrid strategy between State and market, as suggested by Elinor Ostrom and shown by real cases of bottom-up cooperative governance of environmental resources by local populations. But collective management may also not be spontaneous: it is a question of planning "endogenous management institutions" (Ostrom 1990) by promoting participation processes and effective governance systems.

Management by an endogenous institution is similar to the forms of participated management that already exist for certain types of public service, but instead of involving "external" subjects in management who are not concerned in the first person and often represent ideological positions that are difficult to express in operational terms, it is the inhabitants, those directly affected, that are involved.

In the other side, taking the project as an opportunity to activate forms of collective management allows development of the ability to build up rules during learning, which would be lost, as mentioned earlier, if level A2 were missed out, and also to define processes and adaptive and incremental changes, abandoning decisive and deterministic conceptions which actually refuse to acknowledge the meaning itself of each project action in terms of thought for the future.

Reflections and experiences about management rules are a mandatory prerequisites to design processes for collective management. Designers and students have to define the rules in a collective way. The most relevant issue is the experience of stability, because designers are free from market rules and ephemeral trends, and can resist against the economic, environmental and social crisis which in recent years has further demolished certainties, faith and hope, increasing, in a vicious circle, precariousness and instability... resist the crisis through alternative, original proposals to build or restore the relationship with places, favour a feeling of attachment and stimulate the will to take care of one's own life space.

\section{Conclusions: Plan and project as resistance strategy}

To design and resist seem at first sight to be two antithetical terms, incompatible, as the presence of one inhibits the other. Actually the different levels of resistance outlined previously show, even though it may seem illogical, that resistance is creation (Parnet and Deleuze 2005; Aubenas and Benasayag 2002), in that the conditions to resist need to be designed.
Resistance, in this case, opposes every important, stable, axiomatic thought; it is the prelude to creativity, hope and freedom, for it is the task of architecture to produce a hypothesis of order, not to portray the chaos that surrounds us (Masiero 2002); it should aspire again to a permanency that will last through the chronicle of events to become a place of reference (Gregotti 2004).

The project as a resistance strategy accepts the challenge for change launched by the world economic and environmental crisis, seeking new urban forms, new forms of collective management of the environmental and cultural resources, collective goods, urban contexts and the landscape, in order to explore, resisting, the possibilities of existence of other cultural models, forms of democracy and lifestyles, more suitable for these times of uncertainty and instability, bringing back values of frugality, sobriety and solidarity.

At the same time, it helps to reduce or avoid some dangers deriving from the lack of acquisition of the A2 level, a consequence of the current way of learning and of the fluidity and liquidness of the contemporary world.

The entwinement and co-presence of these levels of meaning of the plan and project as resistance strategies can be fruitfully verified in project work which incorporates them as design prerequisites to use and develop all the Batesonian levels of learning, to experiment with stability and to design the transformations of our future life in the best way possible.

Competing interests

The author declares that she has no competing interests.

Received: 30 July 2015 Accepted: 9 February 2016

Published online: 25 February 2016

\section{References}

Alvarex RR (1995) The Mexican-US border: the making of an anthropology of borderlands. Annu Rev Anthropol 24:447-470

Aubenas F, Benasayag M (2002) Résister, c'est créer. La Découverte, Paris Augé M (2003) Le temps en ruines. Galilée, Paris

Bateson G (2000) Verso un'ecologia della mente. Adelphi, Milano, p 324-356 (ed. or. Steps to an ecology of mind. University Chicago Press, Chicago, 1972)

Bauman Z (2002a) Modernità liquida. Laterza, Roma-Bari

Bauman Z (2002b) La società individualizzata. II Mulino, Bologna, p 157-176 (ed. or. The Individualized Society. Polity, Cambridge 2001)

Bhabha H (1990) The third space: interview with Homi Bhabha. In: Rutherford J (ed) Identity: community, culture, difference. Lawrence \& Wishart, London, pp 207-221

Bhabha H (1994) Location of culture. Routledge, London and New York Bhabha H (1996) Aura and Agora: on negotiating rapture and speaking between. In: Francis $\mathrm{R}$ (ed) Negotiating rapture: the power of art to transform lives. Museum of Contemporary Art, Chicago, pp 8-17

Blatter J (2003) Beyond hierarchies and networks: institutional logics and change in transboundary spaces. Governance 16(4):503-526

Ceruti M (1986) II vincolo e la possibilità. Feltrinelli, Milano

Colomina B (2002) Architectureproduction. In: Rattenbury K (ed) This is not architecture. Routledge, London, pp 207-221 
De Kerckhove D (1997) Connected intelligence: the arrival of the web society Sommerville House, Toronto

De Kerckhove D (2001) The architecture of intelligence. Birkhäuser, Basel-Boston

Dewey J (1916) Democracy and education: an introduction to the philosophy of education. MacMillian Company, New York

Frampton K (1983) Towards a critical regionalism: six points for an architecture of resistance. In: Foster $\mathrm{H}$ (ed) The Anti-aesthetic: essays on postmodern culture. Bay Press, Port Townsend, pp 16-30

Frampton K (1986) Luogo, Forma, Identità Culturale. Domus. 673(6)

Gregotti V (2004) L'architettura del realismo critico. Laterza, Bari

Gregotti V (2006) La città e le contraddizioni dei nostri anni, lessons in the theory and technique of architectural design, degree in the science of architecture, academic year 2006/2007, http://www.iuav.it/Facolta/ facolt-di2/NEWS1/eventi-del/lezioni-di/LEZIO

Gregotti V (2008) Caro Koolhaas, basta slogans. Corriere della Sera, 5 August Guattari F (1996) Cartografia schizoanalitica. Millepiani 7, p. 25-32

Gupta A, Ferguson J (1997) Culture, power, place: ethnography at the end of an era. In: Gupta A, Ferguson J (eds) Culture, power, place: explorations in critical anthropology. Duke University Press, Durham, pp 1-29

Gutierrez DG (1999) Migration, emergent ethnicity, and the 'Third Space': the shifting politics of nationalism in greater Mexico". J Am Hist 86(2):481-518

Harvey D (2000) Spaces of hope. Edinburgh University Press, Edinburgh

Hill J (1998a) The illegal architect. Black Dog Publishing Limited, London

Hill J (ed) (1998b) Occupying architecture: between the architect and the user. Routledge, London

Hill J (2003) Actions of architecture: architects and creative users. Routledge, London

Kronenburg R (2007) Flexible, architecture that responds to change, 1st Laurence King, London, p 109

Maciocco G (1995) Dominanti ambientali e progetto dello spazio urbano. Urbanistica 104:76-91

Maciocco G (1999) II progetto ambientale dei territori esterni: prospettive per la pianificazione provinciale. Urbanistica 112:143-155

Maciocco G (2011) Scenarios for a territorial future of the city. In: Maciocco G, Sanna G, Serreli S (eds) The urban potential of external territories. FrancoAngeli, Milano, pp 10-79

Manghi S (2003) Disabituarsi. La conoscenza ordinaria nella società dell'informazione coerente. Documentaria, $4^{\circ}$ Salone di idee, progetti e servizi per la scuola, Modena, 3 September

Manghi S (2004) La conoscenza ecologica. Cortina, Milano

Masiero R (2002) lo scrivo che Gregotti progetta.... In: Associati Gregotti (ed) La costruzione dello spazio pubblico. Alinea, Firenze

Melucci A (2000) Culture in gioco. Differenze per convivere. Bompiani, Milano

Mitchell CT (1993) Redefining designing: from form to experience. Van Nostrand Reinhold, New York

Morin E (1997) Réforme de pensée, transdisciplinarité, réforme de l'Université. Communication au Congrès International "Quelle Université pour demain? Vers une évolution transdisciplinaire de I'Université", 30 April-2 May, Locarno
Morin E (2011) La Voie: Pour l'avenir de I'humanité. Fayard, Paris

Ostrom E (1990) Governing the commons. Cambridge Press, Cambridge

Palermo PC (2000) Autori e paradigmi. Temi e figure emergenti nel corso evolutivo dell'urbanistica italiana. In: Maciocco G, Deplano G, Marchi $\mathrm{G}$ (eds) Etica e pianificazione spaziale. In onore di Fernando Clemente. FrancoAngeli, Milano, pp 25-44

Parnet C, Deleuze G (eds) (2005) Abecedario di Gilles Deleuze. DeriApprodi, Roma

Pittaluga P (2001) Progettare con il territorio: immagini spaziali delle società e pianificazione comunicativa. FrancoAngeli, Milano

Pittaluga P (2008) Images of local societies and projects for space. In: Maciocco $G$ (ed) Territorial future of the city. Springer, The Netherlands

Pittaluga P (2013) Landscape as a common: collective protection and management. In: S (ed) Project and public space. Springer, Dordrecht

Possenti I (2008) Flessibilità e istruzione: una replica a Bauman. Micromega 12:134-142

Rodotà S (2010) Se il mondo perde il senso del bene comune. Repubblica, 10 Agosto

Roger A (1997) Court traité du paysage. NRF, Paris

Rossi A (1966) L'architettura della città. Marsilio, Padova

Routledge P (1996) The third space as critical engagement. Antipode 2(8):399-419

Schön DA (1983) The reflective practitioner. Basic Books, New York

Shannon K (2006) Theory to resistance: landscape urbanism in Europe. In: Waldheim C (ed) The landscape urbanism reader. Princeton Archiectural Press, New York, pp 141-162

Smouts M-C (1998) The region as the new imagined community. In: Le Galès P, Lequesne C (eds) Regions in Europe. Routledge, London, pp 30-38

Soja EW (1989) Postmodern geographies: the reassertion of space in critical social theory. Verso, New York

Soja EW (1996) Thirdspace: journeys to Los Angeles and other real-imagined places. Blackwell, Oxford

Soja EW (2000) Thirdspace: expanding the scope of the geographical imagination. In: Read A (ed) Architecturally speaking. Routledge, London, pp $13-30$

Sorkin M (ed) (1999) Variations on a theme park: the new American city and the end of public space. Hill and Wang, New York

Sorkin M (2001) The theming of the City. Lotus 109:16-17

Tagliagambe S (2008) Landscape as a regenerative structure of a fragmented territory. In: Maciocco G (ed) Urban landscape perspectives. SpringerVerlag, Berlin, Heidelberg, New York, pp 61-79

Tangkjær C, Jonsson O (2005) Cross border regions as involutionary spaces. Paper presented at the Inaugural Nordic Geographers Meeting, Lund

Turner NJ, Davidson-Hunt IJ, O'Flaherty M (2003) Living on the edge: ecological and cultural edges as sources of diversity for social-ecological resilience. Hum Ecol 31(3):439-461 